\title{
Jovens em Contextos Sociais Desfavoráveis e Sucesso Escolar no Ensino Médio
}

\author{
Vanessa Gomes de Castro' \\ Fernando Tavares Júnior ${ }^{1}$
}

'Universidade Federal de Juiz de Fora (UFJF), Juiz de Fora/MG - Brasil

RESUMO - Jovens em Contextos Sociais Desfavoráveis e Sucesso Escolar no Ensino Médio. Analisa-se o perfil dos jovens em contextos sociais desfavoráveis que chegaram com sucesso ao terceiro ano do ensino médio. Sucesso é aqui compreendido como a chegada do aluno ao $3^{\circ}$ ano do ensino médio em idade apropriada, sem ter sido reprovado e/ou abandonado à escola durante sua trajetória. Investigam-se os determinantes sociológicos desse sucesso em contextos sociais desfavoráveis. Para tanto, utiliza-se microdados da edição 2011 do Sistema de Avaliação da Educação Básica. Apesar de prognósticos teóricos e factuais contrários, constata-se que muitos indivíduos nas condições sociais mais desfavoráveis alcançam o sucesso escolar. Observa-se que o background familiar influencia, porém, não determina a realização escolar dos indivíduos.

Palavras-chave: Jovens. Ensino Médio. Sucesso Escolar. Trajetórias Escolares. Contextos Desfavoráveis.

ABSTRACT - Youth in Unfavorable Social Contexts and Educational Attainment in Secondary Education. This paper analyses the profile of youth in unfavorable social contexts who have achieved educational attainment in their secondary education. Attainment is here understood as the completion of the 3rd year of secondary education at the appropriate age, without having failed and/or dropped the school during the educational trajectory. We investigate sociological determinants of the educational attainment in unfavorable social contexts. We use micro-data from the Basic Education Evaluation System, 2011 edition. Despite contrary theoretical and factual predictions, we have found that many individuals in the most unfavorable social conditions achieve educational attainment. We observed that the family background influences, but does not define the educational attainment of the individuals.

Keywords: Youth. Secondary Education. Educational Attainment. Educational Trajectory. Unfavorable Contexts.

Educação \& Realidade, Porto Alegre, v. 41, n. 1, p. 239-258, jan./mar. 2016. 239 http://dx.doi.org/10.1590/2175-623656080 


\section{Introdução}

No Brasil, muitos dos desafios contemporâneos da educação básica referem-se ao ensino médio. Dentre esses desafios, a universalização do ensino médio, com qualidade e equidade, a correção do fluxo e dos baixos índices de aprendizagem, a promoção de uma educação integral, bem como a adequação do extenso currículo à realidade, ao mercado de trabalho, aos interesses dos jovens e da sociedade brasileira contemporânea, representam grandes desafios às políticas públicas educacionais. Embora nas últimas décadas o país tenha experimentado um avanço nos indicadores de acesso e permanência nesta etapa, muitos jovens com idades entre 15 e 17 anos, os quais deveriam estar cursando o ensino médio, quando não estão fora da escola, estão em situação de defasagem escolar. Fato que se agrava entre os jovens em condições sociais desfavoráveis, isto é, entre os mais pobres, não brancos, cujos pais têm pouca escolarização, ou sequer tiveram oportunidades educacionais.

Frente a esse quadro, nos últimos anos, o ensino médio brasileiro tem sido alvo de acirradas discussões, principalmente no que diz respeito à necessidade de reforma curricular. De um lado, pesquisadores e entidades argumentam que o ensino médio possui um extenso currículo, composto de disciplinas acadêmicas obrigatórias, mesmo para os jovens que escolhem uma formação profissional de nível técnico, defendendo questões como a necessidade de um currículo mínimo obrigatório e a possibilidade de completá-lo através de disciplinas eletivas, bem como articulá-lo à educação profissional (Castro, 2011). De outro lado, pesquisadores e entidades criticam a ausência de interlocução entre o Ministério da Educação e o Congresso Nacional, cujas propostas de reformulação do ensino médio sugerem que o currículo deve ser moldado em quatro áreas do conhecimento - linguagens, matemática, ciências da natureza, ciências humanas - além da formação profissional, constituindo uma proposta fragmentada e culminando em uma escola dual, que prepara para o vestibular ou para o mundo do trabalho, mas que não resolve problemas mais complexos e estruturais do sistema de ensino (Carrano, 2014). Conforme observado por Dubet (2002), em uma sociedade complexa e diversificada o programa institucional da escola - de homogeneidade de valores e princípios - não é mais possível. É preciso oferecer um modelo alternativo, moderno e democrático, que respeite as pluralidades.

De uma forma ou de outra, muito do que tem sido discutido visa tornar o ensino médio uma etapa mais atraente, comprometida com os desafios da sociedade do conhecimento, em rede e tecnológica (Castells, 2002), tal como expresso pelo Plano Nacional de Educação (Brasil, 2014). Embora o número de alunos matriculados no ensino médio tenha aumentado significativamente nos últimos anos, menos de $60 \%$ dos jovens conseguem terminar essa etapa e uma fração ainda menor

240 Educação \& Realidade, Porto Alegre, v. 41, n. 1, p. 239-258, jan./mar. 2016. 
consegue ingressar no ensino superior. O ensino médio acumula as carências das etapas anteriores, que vão desde falhas no acesso à escola, na alfabetização e no aprendizado durante o ensino fundamental, até problemas para a conclusão das demais séries (Castro, 2011). Tornou-se urgente vencer as barreiras de rendimento e desempenho para a construção de gerações mais incluídas, produtivas e com acesso menos desigual às oportunidades. Enquanto muitos jovens em contextos sociais desfavoráveis sentem-se pouco motivados a concluir essa etapa, cultivando baixas expectativas em relação às possibilidades materiais e simbólicas do diploma, jovens pertencentes a parcelas privilegiadas da sociedade tendem a encará-lo como um trampolim para a universidade, reforçando o hiato social.

Como já enfatizado por Krawczyk (2011), o ensino médio brasileiro é o nível de ensino que provoca os debates mais polêmicos, seja pelos persistentes problemas de acesso e permanência, seja pela qualidade da educação oferecida, ou pela discussão sobre a sua identidade. Fala-se de perda de identidade, quando na verdade, o ensino médio nunca teve uma identidade muito clara para além de seu papel propedêutico. Para os jovens dos médios e altos segmentos sociais, cursar o ensino médio é algo quase natural, visto que o diploma superior faz parte de sua estrutura de capitais culturais e simbólicos, tanto em função do caráter reprodutivo (Bourdieu, 1970), quanto do consumo defensivo (Hirsch, 1979). Para esses jovens, há uma motivação intrínseca às recompensas e à própria trajetória de seu grupo social de referência, bem como um amplo aparato de apoio (familiar, escolar, etc.) à sua trajetória educacional.

A questão central recai sobre os jovens oriundos de camadas sociais mais pobres, para os quais o ensino médio não faz parte de seu capital cultural e sua experiência familiar, onde esses jovens nem sempre são cobrados por não darem continuidade aos estudos. Para esses jovens, a realização dos objetivos modernos e democráticos da educação é limitada pelos empecilhos impostos por suas origens sociais, aliados às desigualdades de oportunidades. O ensino médio praticamente não faz parte de seu capital cultural nem de sua experiência familiar, muitas vezes não havendo cobranças ou grandes expectativas de que realizem longa trajetória educacional. Embora o Brasil tenha experimentado uma mobilidade educacional expressiva nas últimas décadas, com sucessivas gerações mais jovens mais escolarizadas que seus pais, ainda há uma preservação significativa de desigualdades, tanto vertical, quanto horizontal (Tavares Jr., 2007). Mesmo os jovens que experimentam essa mobilidade encontram muitas dificuldades para compreender o sentido da vida escolar e pensar no mundo do trabalho a partir da escola (Krawczyk, 2011). Frente a esse quadro, considerar os tempos, as disritmias, as fases da vida, as transições e as singularidades das biografias, conforme enfatizado por Pais e Ferreira (2010) e Ferreira e Nunes (2014), é fundamental para compreendermos os sentidos que os jovens atribuem à sua escolarização.

Educação \& Realidade, Porto Alegre, v. 41, n. 1, p. 239-258, jan./mar. 2016. 
Os problemas de acesso, permanência, fluxo e conclusão do ensino médio no país, amplamente evidenciados pela literatura científica, justificam a definição de sucesso escolar aqui adotada, qual seja a chegada do aluno ao terceiro ano do ensino médio em idade apropriada, sem ter sido reprovado e sem ter abandonado a escola durante sua trajetória. Apesar de muitos estudos abordarem o sucesso escolar a partir de categorias de fluxo (como aprovação, reprovação e distorção idade/ série) e/ou proficiência (desempenho em testes padronizados), optou-se por caracterizar o sucesso escolar a partir do alcance educacional dos jovens, representado por sua chegada ao terceiro ano do ensino médio. Embora a conclusão do ensino médio seja condição indispensável ao ingresso no ensino superior, além de potencializar melhores oportunidades no mercado de trabalho, as marcantes desigualdades presentes na sociedade brasileira, juntamente com os problemas do próprio sistema educacional, comprometem fortemente as trajetórias escolares dos indivíduos pertencentes a grupos sociais menos favorecidos, não somente no que se refere à conclusão do ensino médio, mas toda sua escolarização e inserção social.

Ressalta-se que na Sociologia da Educação não há unanimidade quanto à definição de sucesso/insucesso escolar. Contudo, de acordo com Nogueira e Fortes (2004), em termos absolutos é possível definir sucesso/insucesso escolar em função da distância percorrida pelo indivíduo no sistema de ensino, do tempo gasto e da natureza mais ou menos prestigiada do percurso realizado. Nesses termos, os casos de sucesso são definidos como aqueles em que os indivíduos alcançam os ramos superiores e mais prestigiados do sistema de ensino no menor tempo possível. Outra possibilidade de análise implica definir sucesso/ insucesso escolar em termos relativos. Nesses termos, o sucesso escolar é representado pelo aluno que teria tudo para fracassar na escola devido à sua posição social desfavorável, conforme apontado pela literatura científica, porém consegue obter êxito em sua trajetória, contrariando as estatísticas, fugindo à regra (Nogueira; Fortes, 2004). Posto isso, nesta investigação o sucesso escolar é definido em termos relativos.

Embora a definição de sucesso escolar aqui adotada possa parecer redutora no que tange a capturação de todas as dimensões subjacentes ao processo de construção das trajetórias biográficas e escolares (Vieira; Pappámikail; Nunes, 2012), tal definição foi adotada justamente porque as dimensões subjacentes são demasiadamente amplas e complexas para se investigar, optando-se por um determinado recorte como ponto de partida. Vieira, Pappámikail e Nunes (2012) destacam que investigar as diversas modalidades de trajetórias escolares, mais ou menos agitadas, marcadas por mobilidades, rupturas e reversibilidades que fogem à lógica convencional, é fundamental para entender as várias modalidades de sucesso escolar. Nesse sentido, adotar definições conceituais e abordagens metodológicas diversificadas é indispensável. Assim, nesta investigação optou-se por examinar as exceções que com- 
provam a regra, isto é, os alunos de escolas públicas, não brancos, com baixo nível sócio econômico, oriundos de famílias privadas do acesso à escola (mães com pouca ou nenhuma escolarização), que a pesar das condições sociais desfavoráveis, obtiveram sucesso escolar, isto é, chegaram ao terceiro ano do ensino médio em idade apropriada, sem ter sido reprovado e sem ter abandonado a escola ao longo de sua trajetória. Essas clivagens sociais são muito significativas e relevantes para análise sociológica da educação brasileira.

\section{Discussão Teórica}

Buscou-se observar o perfil e as características do background familiar dos jovens em condições sociais desfavoráveis que realizaram com sucesso suas trajetórias escolares até o terceiro ano do ensino médio. O background familiar é composto por características socioeconômicas mensuráveis, as quais proporcionam aos indivíduos um melhor aproveitamento dos recursos disponíveis. Refere-se a um conjunto de elementos presentes no ambiente familiar, que se ajustam aos indivíduos a fim de produzirem melhores resultados. Segundo larga revisão teórica de Nogueira (1990), a influência do background familiar sobre a experiência educacional dos indivíduos ocupa um lugar de destaque na Sociologia da Educação, desde o Coleman Report (Coleman et al., 1966). O citado Relatório Coleman (Coleman et al., 1966) pesquisou em larga escala alunos norte-americanos no intuito de investigar os resultados educacionais e relacioná-los a características sociais e institucionais. Verificou-se que as diferenças sociais, econômicas e culturais traduziam-se em diferenças de desempenho, interferindo na trajetória escolar desses jovens. Suas conclusões apontaram o peso do background familiar e das condições socioeconômicas dos alunos em seu sucesso ou fracasso educacional (Nogueira, 1990).

Desde os anos sessenta, além do Relatório Coleman (Coleman et al., 1966), várias pesquisas de larga escala ao redor do mundo, por exemplo o Relatório Plowden (Plowden..., 1967), na Grã-Bretanha, dentre outros, buscaram calcular as taxas de escolarização segundo as categorias socioeconômicas, bem como as disparidades sociais quanto às oportunidades de acesso e sucesso na escola. A partir de investigações como essas, houve o reconhecimento de que o desempenho escolar não dependia somente dos dons individuais, das características institucionais (escolares) ou das políticas educacionais, mas, fortemente, da origem social dos alunos e suas famílias (Nogueira, 1990). Desde então, várias teorias buscam explicar a produção social da educação em seus diferentes meandros, fundamentadas em distintos argumentos e metodologias. Muitas dessas teorias perpassaram, de forma dialética, pela via da reprodução ou da transformação social. Dentre essas, destacamos as Teorias do Capital Humano, de Gary Becker (2002), publicada originalmente em 1964, e Theodore Schultz (1970); a Reprodução, em 
Pierre Bourdieu e Jean-Claude Passeron (1970), publicada no Brasil em 1975; e as proposições de autores como Raymond Boudon (1981) e John Goldthorpe (2010), as quais serão discutidas brevemente a seguir.

Ao final dos anos cinquenta, as Teorias do Capital Humano afirmaram uma perspectiva otimista e meritocrática do papel da educação nas modernas sociedades industriais, ao defender que a realização social seria retorno direto dos investimentos em educação e outros méritos individuais. Nessa perspectiva, o investimento em capital humano (educação/qualificação) é a chave para resolver dilemas sociais relevantes, como o subdesenvolvimento e as desigualdades. O nível educacional torna-se o principal critério de seleção social, em que os indivíduos concorrem de forma igualitária a partir das credenciais educacionais adquiridas. Recomenda-se o investimento público e pessoal em educação para promover o crescimento econômico e equalizar as oportunidades sociais. Sob essa ótica, a escola realizaria, ou pelo menos potencializaria a igualdade de oportunidades. Porém, no geral, se reconhece que os mais pobres são sempre os mais prejudicados em suas aquisições educacionais (Becker, 2002; Schultz, 1970).

Algumas das principais críticas às Teorias do Capital Humano partiram das teorias reprodutivistas dos anos 1960 e 1970, as quais defenderam que os sistemas de ensino constituem espaços reprodutores das desigualdades, legitimadores das diferenças estruturais observadas entre as classes desde seu background. Portanto, além de pouco efetivos na mudança da estrutura social, mesmo em períodos de expansão econômica e democratização das oportunidades, os sistemas de ensino cumpririam o papel inverso, ou seja, de preservar as diferenças entre as classes e assim reproduzir a sociedade e suas desigualdades. O sistema de ensino atuaria como um mecanismo de internalização de valores, normas e comportamentos, ditados pelas classes dominantes, além de um produtor de certo tipo de trabalhador para o mundo capitalista (Nogueira, 1990).

O principal expoente desta corrente foi Pierre Bourdieu. Bourdieu e Passeron (1970), os quais caracterizaram a educação como um mecanismo de reprodução social, ao investigarem os meios através dos quais as classes dominantes (incluindo médias/altas) efetivamente se apropriam e concentram os distintos recursos em benefício próprio, especialmente no intuito de preservar sua posição social de vantagem. Nessa perspectiva, a reprodução cultural das classes passaria pelo sistema educacional, configurado em favor da manutenção das classes dominantes. O sistema educacional não seria um meio de desenvolver talentos e potencialidades, ou de ampliação de oportunidades através da meritocracia, mas sim uma agência de controle político-social necessária à manutenção das estruturas de classes na sociedade (Bourdieu, 1979). A escola seria um aparelho reprodutor das estruturas sociais, opondo-se, portanto, às previsões das Teorias do Capital Humano de que a escola realizaria a igualdade de oportunidades. 
Na perspectiva da reprodução, os alunos provenientes de classes sociais favorecidas obteriam mais sucesso educacional em função dos ajustes implícitos entre o currículo escolar e as exigências comportamentais da escola de um lado; e o comportamento simbólico típicos dessas classes, eleito tacitamente como correto ou erudito, de outro. Assim, os alunos provenientes de classes sociais favorecidas adequar-se-iam mais facilmente às exigências escolares devido ao ajustamento com seu habitus de classe, ao passo que os alunos provenientes das classes sociais desfavorecidas seriam prejudicados e levados ao fracasso escolar em razão de seu habitus de classe inadequado perante as exigências escolares. A isso se soma a limitação de outras formas de capital, como o menor estoque de capital econômico e respectivos recursos, bens e serviços, relevantes para o desenvolvimento educacional. Desta forma, os indivíduos provenientes das camadas menos favorecidas da sociedade estariam muito mais propensos ao insucesso escolar, refutando as expectativas de transformação social a partir da escola (Nogueira; Nogueira, 2004).

Ainda nos anos 1970, Raymond Boudon argumentou de forma ligeiramente distinta, defendendo que embora a posição social exerça grandes influências, ela não determina o futuro escolar dos indivíduos. As sociedades não tenderiam fatalmente à reprodução. Embora a manutenção das posições de classe seja amplamente observada, ao longo do tempo também se observa a transformação dessas posições e da estrutura social como um todo, em ritmo e fluidez muito aquém do previsto pelas teorias liberais, mas também em direções potencialmente mais promissoras do que imaginado pelos reprodutivistas. Alguns dos limites à transformação estariam nas próprias decisões, sejam elas coletivas, expressas em políticas públicas ou investimentos de classe, ou individuais, derivadas das famílias e seus membros.

Sob essa ótica, os indivíduos elegeriam objetivos sociais e analisariam os meios ideais para persegui-los, avaliando, em certa medida, os prováveis custos, riscos e benefícios de suas decisões. Pessoas e grupos orientar-se-iam por normas sociais e pela expressão de valores culturais, conhecendo, até certo ponto, sua sociedade e os constrangimentos que caracterizam cada situação, sendo capazes de agir de forma autônoma em favor dos seus interesses e de maneira mais ou menos adequada em relação à situação social em que se encontram, uma vez que conheceriam, ainda que de forma limitada, os constrangimentos sociais inerentes a cada decisão. Sendo assim, as origens sociais influenciam, mas não determinam as trajetórias educacionais dos indivíduos. A origem social confere distintos significados aos riscos, custos e benefícios correspondentes à aquisição de um dado nível de estudo, contrariando as hipóteses das Teorias do Capital Humano de que a escola sozinha seria capaz de realizar a igualdade de oportunidades, bem como as hipóteses da Reprodução, em que os indivíduos em situação social de desvantagem estariam fadados ao fracasso escolar.

Educação \& Realidade, Porto Alegre, v. 41, n. 1, p. 239-258, jan./mar. 2016. 
Em seus estudos sobre as desigualdades de oportunidades Boudon (1981) argumentou sobre os efeitos primários, em que há o predomínio das influências culturais de classe em relação às expectativas de desempenho cognitivo e sucesso educacional do individuo desde o inicio de sua vida escolar; e os efeitos secundários, que operariam através das decisões tomadas pelos indivíduos (e famílias) em relação ao prolongamento ou não de sua trajetória escolar, a partir da análise das possibilidades de conversão dos diplomas em realização socioeconômica, isto é, dos custos, riscos e benefícios. Goldthorpe (2010) prossegue em concordância com Boudon (1981), porém defendendo que estaria nos efeitos secundários o centro das atenções em relação às diferenças educacionais entre as classes. Segundo Tavares Jr. (2007), o modelo defendido por Goldthorpe (2010), inspirado no modelo de Boudon (1981), destaca a importância da tomada de decisão individual, do ethos e da análise dos custos, riscos e benefícios da educação enquanto um investimento pessoal e familiar. As regularidades na estrutura social não seriam decorrentes apenas da reprodução estrutural, mas de como se dão as escolhas e como se processam as relações de custo/benefício para cada classe (Tavares Jr., 2007).

É possível observar que muitos jovens, mesmo pertencendo a classes sociais menos favorecidas, almejam os níveis educacionais mais elevados e a esperada mobilidade social, mesmo sem os meios ideais para persegui-los, avaliando os prováveis custos, riscos e benefícios, descrevendo trajetórias escolares heterogêneas. Capazes de agir de forma autônoma em favor dos seus interesses, apesar de não serem totalmente esclarecidos, muitos desses jovens adaptam-se às oportunidades e constrangimentos que caracterizam sua situação social (Goldthorpe, 2010). Esses jovens não percorrem a trajetória usual de seus pares de origem social desfavorável, nem a dos indivíduos das classes médias/ altas, realizando um percurso novo e criativo, construído a partir das oportunidades observadas, com estratégias, por vezes, inovadoras (isto é, nunca antes empreendidas por outros membros do grupo), possíveis de realização em função de oportunidades, por exemplo, de acesso e condições de permanência no sistema de ensino.

O objetivo geral desse trabalho é examinar os possíveis determinantes do sucesso escolar entre esses jovens em condições sociais desfavoráveis, que tendem à reprodução, mas também tendem à mobilidade. Nesse sentido, destaca-se o papel diagnóstico e exploratório desse trabalho. Os objetivos específicos são analisar as características demográficas dos alunos que chegaram ao terceiro ano do ensino médio, bem como as desigualdades existentes; identificar os casos de sucesso escolar entre os indivíduos com pior perfil socioeconômico; e analisar os hábitos e as características do background familiar desses indivíduos com pior perfil socioeconômico que atingiram o sucesso escolar.

Pretendeu-se assim identificar os possíveis determinantes dessas improváveis trajetórias bem-sucedidas. Os microdados utilizados são 
do Sistema de Avaliação da Educação Básica (SAEB), edição 2011, uma vez que ainda não foram disponibilizados dados mais atuais. Ressalta-se que não foram encontrados estudos anteriores no Brasil que tenham proposto esse recorte com a análise de dados empíricos aqui desenvolvidos. Aliar densidade teórico-conceitual à investigação empírica robusta foi um dos objetivos metodológicos que norteou o trabalho. Dada a originalidade da proposição e os limites práticos da pesquisa, foram encontrados desafios substantivos à sua operacionalização, que pretendem ser superados em estudos posteriores, alguns já em curso.

\section{Metodologia}

Na primeira etapa, a população efetivamente investigada foi delimitada por meio da remoção dos questionários não aplicados ou não preenchidos da base de dados, principalmente os referentes às informações testadas. Feito isso, seguiu-se a análise descritiva dos alunos matriculados no terceiro ano do ensino médio, no que se refere a aspectos demográficos como sexo, cor, ano de nascimento, região, dependência administrativa e localização. Feita esta análise geral, o passo seguinte foi dividir os alunos em dois grupos distintos: o grupo daqueles que nunca foram reprovados, nunca abandonaram a escola e chegaram ao terceiro ano do ensino médio em idade razoável, com trajetórias contínuas e regulares, considerados casos de sucesso; e o segundo grupo, formado por alunos com trajetórias irregulares e defasagem idade/série, considerados casos de não sucesso escolar. Nessa fase exploratória, também foram removidos da amostra os casos com respostas incongruentes.

Na segunda etapa, os alunos foram redivididos em grupos quasi homogêneos, considerando a cor, a escolaridade da mãe e o acesso a bens de consumo, realizando-se uma análise de cluster. Tal procedimento estatístico é utilizado para classificar os casos por observação das semelhanças e diferenças, sendo uma ferramenta de triagem dos diferentes casos em grupos, de forma que o grau de associação entre os casos seja máximo, se eles pertencerem ao mesmo grupo, e mínimo, do contrário. Assim, os clusters foram distribuídos em grupos distintos segundo a cor, a escolaridade da mãe e o acesso a bens de consumo. Nessa fase, os clusters também foram divididos segundo o sucesso e o não sucesso escolar. Formaram-se seis grupos com perfis antagônicos, cujo grupo 01 constituiu-se por não brancos, com mães menos escolarizadas e com o pior nível socioeconômico, ao passo que o grupo 05, por exemplo, foi formado pelo oposto: brancos, com mães mais escolarizadas e o melhor nível socioeconômico. Os demais grupos foram formados por perfis intermediários. Após esse procedimento, definiu-se o grupo 01 como sujeito central desta investigação.

Uma vez que o grupo 01 tornou-se o foco desta pesquisa, dada sua situação de desvantagem social, o passo seguinte foi analisar e com- 
parar, a partir de estatísticas descritivas, as características individuais e do background familiar dos casos de sucesso e não sucesso escolar, pertencentes a esse grupo. Para isso, foram utilizadas as respostas dadas ao questionário socioeconômico do SAEB. Objetivou-se identificar características contrastantes entre indivíduos com a mesma origem social desfavorável, para tentar correlacioná-las à descrição de trajetórias distintas. Logicamente, a maior distinção refere-se àqueles que sequer chegaram ao ensino médio. Todavia, mesmo trajetórias retardatárias têm muito a ensinar sobre o processo de produção das desigualdades.

\section{Resultados}

A base de dados do SAEB 2011, disponibilizada pelo INEP (Instituto Nacional de Estudos e Pesquisas Educacionais Anísio Teixeira), apresenta um total de 103.009 alunos matriculados no terceiro ano do ensino médio. Porém, retirados os questionários não aplicados ou não preenchidos, a população efetivamente investigada representa 69.496 casos. Dentre esses, 66.861 alunos constam com pelo menos os dados demográficos preenchidos, tais como sexo, cor, ano de nascimento, região, dependência administrativa e localização. Em relação ao sexo, verificou-se $56,2 \%$ de mulheres matriculadas no terceiro ano do ensino médio e 43,8\% de homens. Conforme já evidenciado pela literatura cientifica, no geral, as mulheres tendem a realizar trajetórias escolares mais prolongadas que os homens, em razão, por exemplo, de serem menos pressionadas a ingressar mais cedo no mercado de trabalho, adentrando mais tardiamente com um nível mais elevado de educação (Hasenbalg; Silva, 2003).

Quanto aos grupos raciais, verifica-se que a população negra representa $9,5 \%$ dos casos, a branca $40,3 \%$, enquanto que a população parda representa a maioria, totalizando $44,3 \%$. De acordo com o Instituto Brasileiro de Geografia e Estatística (IBGE), nos últimos anos houve um aumento do número de pessoas que se autodeclaram pardas ou negras. O número de pardos cresceu de $38,5 \%$ no Censo de 2000 , para $43,1 \%$ no Censo de 2010. A proporção de negros também subiu de $6,2 \%$ para 7,6\%, no mesmo período. A militância dos movimentos negros em prol da igualdade racial, do reconhecimento de sua identidade, de sua cidadania e de seus direitos, com agenda política própria e a articulação com outros movimentos sociais, bem como a implementação de políticas de ações afirmativas (por exemplo, as cotas raciais) e a valorização da cultura negra pelos meios de comunicação, podem ser fatores que contribuíram para que mais pessoas se autodeclarassem pardas e negras.

No que tange o ano de nascimento, nota-se que 53\% dos alunos matriculados no terceiro ano do ensino médio em 2011 nasceram em 1994 ou depois, aparentemente não havendo defasagem idade/série entre esses casos, na medida em que os nascidos em 1994, que cursaram trajetórias contínuas e regulares, de fato, deveriam estar no terceiro ano

248 Educação \& Realidade, Porto Alegre, v. 41, n. 1, p. 239-258, jan./mar. 2016. 
do ensino médio em 2011, aos 17 anos de idade, com aproximadamente 11 anos de escolaridade. Tavares Jr., Feres e Freguglia (2014) pontuam que um Sistema eficiente ou de bom rendimento é aquele em que as crianças completam o nível fundamental em 09 anos e o nível médio em 03 anos. Em geral, a reflexão acerca do rendimento centraliza-se nas categorias de fluxo, como aprovação, reprovação, evasão e distorção idade-série. Tais indicadores estão relacionados, sendo a reprovação e a evasão as principais causas da distorção idade-série. Isso leva a crer que os alunos que sofrem retenções ou evadem em algum momento da escolarização básica, tendem a não chegar ao final do terceiro ano do ensino médio.

Segundo Mont'Alvão (2011), nos últimos anos o ensino médio passou de um patamar de um milhão para mais de sete milhões de estudantes matriculados. As maiores taxas de incremento nesse nível de ensino encontram-se na região Nordeste, que entre 1997 e 2002, apresentou elevação de $92 \%$ no número de matrículas. Até então, essa região concentrava o maior contingente populacional fora do sistema de ensino. De acordo com os dados do SAEB, em 2011, a região Nordeste concentrou 32,8\% de alunos matriculados no terceiro ano do ensino médio, seguida da região Sudeste com 22,9\%, Norte com 17,3\%, Centro-Oeste $14,8 \%$ e Sul 12,1\%. Todavia, a amostra utilizada não foi ponderada, comprometendo a generalização dos resultados.

No que se refere à dependência administrativa, nota-se que a rede estadual, que tem prevista esta responsabilidade em função da divisão das atribuições dos níveis de ensino entre os entes federados, concentra, junto com a rede privada, o maior número de alunos matriculados no terceiro ano do ensino médio: rede estadual com 57,9\% e privada com $35,2 \%$. No que diz respeito à localização, a área urbana concentra o maior número de alunos matriculados do ensino médio (93,9\%), como era de se esperar, dadas as dificuldades de acesso ao ensino médio no meio rural.

Dos 66.861 alunos que chegaram ao terceiro ano do ensino médio, constando com seus dados demográficos preenchidos, como visto acima, 65.658 casos responderam ao item sobre reprovação e abandono escolar. Desse total, apenas 46.112 alunos responderam nunca terem sido reprovados e nunca terem abandonado a escola durante o ano letivo. Todavia, ao considerarmos a idade, os casos de sucesso tornam-se menos comuns. Ao examinarmos as trajetórias contínuas e regulares, em que nunca houve reprovação e abandono/evasão, com os alunos chegando ao terceiro ano do ensino médio em idade razoável (aos 17 anos), retirados os questionários com respostas incongruentes, os casos de sucesso totalizam apenas 34.067 alunos, correspondendo aproximadamente $50 \%$ do banco. Um dado preocupante, na medida em que somente a metade dos alunos matriculados no $3^{\circ}$ ano do ensino médio em 2011, cursaram trajetórias contínuas, regulares e aparentemente sem defasagem idade/série, sendo considerados por esta pesquisa casos de 
sucesso. Desta forma, verificou-se na base de dados 34.067 casos de sucesso e 31.989 casos de não sucesso escolar. Observa-se que a maioria dos alunos que chegaram ao terceiro ano do ensino médio nunca foram reprovados, ou foram reprovados poucas vezes. O fluxo irregular (não aprovação) no ensino fundamental permanece como o maior obstáculo ao sucesso escolar no ensino médio.

Ao investigar as trajetórias escolares de vinte e sete alunos das camadas populares na França, bem como sua biografia familiar, Lahire (1997) observou que a improbabilidade estatística de sucesso escolar está mais relacionada às situações de grandes dificuldades escolares, cada vez menos frequentes nas etapas iniciais de uma escolarização que se prolongou nos últimos anos. De fato, se por um lado é mais provável encontrar crianças dos meios populares dentre os alunos que tiveram pelo menos uma repetência nos anos iniciais da educação básica, por outro lado não é absolutamente impossível encontrar crianças vindas destes mesmos meios com escolaridade sem repetência. Os descompassos se deslocam cada vez mais para os anos finais da educação básica. Ao investigar essas crianças, Lahire (1997) observou que somente a posse de capital econômico e cultural não explica o sucesso escolar. Para compreender os resultados escolares, é preciso identificar configurações complexas e redes de interdependência.

Ao redistribuirmos os alunos considerando a cor, a escolaridade da mãe e o acesso a bens de consumo (análise de cluster), o número de casos reduziu-se relativamente, devido ao não preenchimento do formulário no que diz respeito às informações testadas. Nesta etapa, formaram-se seis grupos com perfis antagônicos, cujo grupo 01 foi formado por não brancos, com mães menos escolarizadas e com o pior perfil socioeconômico, e o grupo 05 , por exemplo, foi constituído pelo oposto, brancos, com mães mais escolarizadas e com o melhor perfil socioeconômico. Os demais grupos foram constituídos por perfis intermediários, não sendo o foco dessa pesquisa:

Tabela 1 - Distribuição dos Grupos

\begin{tabular}{|c|c|c|c|}
\hline GRUPOS & N & \% VÁLIDO & \% TOTAL \\
\hline 1 & 11761 & $20,4 \%$ & $11,4 \%$ \\
\hline 2 & 4388 & $7,6 \%$ & $4,3 \%$ \\
\hline 3 & 6053 & $10,5 \%$ & $5,9 \%$ \\
\hline 4 & 3214 & $5,6 \%$ & $3,1 \%$ \\
\hline 5 & 17050 & $29,6 \%$ & $16,6 \%$ \\
\hline 6 & 15061 & $26,2 \%$ & $14,6 \%$ \\
\hline Total & 57527 & $100,0 \%$ & $55,8 \%$ \\
\hline Casos excluídos & 45482 & & $44,2 \%$ \\
\hline \multicolumn{2}{|c|}{ TOTAL Fonte: INEP (2011). Tabulação própria. } \\
\hline
\end{tabular}


Uma vez que o grupo 01 foi formado por indivíduos não brancos, com mães pouco escolarizadas e com acesso restrito a bens de consumo, ele tornou-se alvo dessa investigação. Assim, os casos desse grupo foram comparados entre si, no intuito de se investigar os possíveis determinantes do sucesso e não sucesso escolar dentre os indivíduos em situação de desvantagem social. Removidos os casos com respostas aparentemente inconsistentes, o grupo 01 contou com um total de 11.494 casos, dos quais 3.914 (34\%) foram casos de sucesso - alunos que chegaram ao terceiro ano do ensino médio aos 17 anos, sem terem sido reprovados e/ou abandonado à escola durante sua trajetória - e 7.580 (66\%), casos de não sucesso escolar - alunos matriculados no terceiro ano do ensino médio com defasagem de idade. Esses números confirmam a primeira hipótese desta pesquisa de que, no Brasil, o sucesso escolar é extremamente dificultado em razão das desigualdades persistentes na sociedade.

Dentre o grupo 01, observa-se que hábitos de leitura e outros consumos culturais revelam influencia ambígua sobre o sucesso escolar. No caso do hábito de leitura, os casos de sucesso aparentemente leem menos. Em relação à leitura de jornal, por exemplo, observa-se, curiosamente, que aqueles que não obtiveram sucesso escolar leem mais jornal do que aqueles que atingiram o sucesso escolar. $\mathrm{O}$ mesmo se aplica aos outros tipos de leitura, ou seja, no geral, os casos de sucesso alegam ler menos, ainda que as diferenças para os casos de não sucesso escolar sejam sutis e discretas:

Tabela 2 - Leitura de Jornal

\begin{tabular}{|c|c|c|c|}
\hline \multirow{2}{*}{ Leitura de jornal } & \multicolumn{2}{|c|}{ Sucesso escolar } & \multirow{2}{*}{ Total } \\
\cline { 2 - 3 } & Não & Sim & \multirow{2}{*}{ Tor } \\
\hline \multirow{2}{*}{ Sempre ou quase sempre } & 2.020 & 784 & 2.804 \\
& $30.6 \%$ & $21.3 \%$ & $27.3 \%$ \\
\hline \multirow{2}{*}{ De vez em quando } & 2.684 & 1.639 & 4.323 \\
& $40.6 \%$ & $44.6 \%$ & $42.1 \%$ \\
\hline \multirow{2}{*}{ Nunca ou quase nunca } & 1.899 & 1.251 & 3.150 \\
& $28.8 \%$ & $34.1 \%$ & $30.7 \%$ \\
\hline \multirow{2}{*}{ Total } & 6.603 & 3.674 & 10.277 \\
& $100.0 \%$ & $100.0 \%$ & $100.0 \%$ \\
\hline
\end{tabular}

Fonte: INEP (2011). 
Jovens em Contextos Sociais Desfavoráveis e Sucesso Escolar no Ensino Médio

Tabela 3 - Leitura de Revistas de Informação Geral

\begin{tabular}{|c|c|c|c|}
\hline \multirow{2}{*}{$\begin{array}{c}\text { Leitura de revistas de informação } \\
\text { geral }\end{array}$} & \multicolumn{2}{|c|}{ Sucesso escolar } & \multirow{2}{*}{ Total } \\
\cline { 2 - 3 } & Não & Sim & \\
\hline \multirow{2}{*}{ Sempre ou quase sempre } & 2.053 & 961 & 3.014 \\
& $31.4 \%$ & $26.1 \%$ & $29.5 \%$ \\
\hline \multirow{2}{*}{ De vez em quando } & 2.836 & 1.800 & 4.636 \\
& $43.3 \%$ & $48.9 \%$ & $45.4 \%$ \\
\hline \multirow{2}{*}{ Nunca ou quase nunca } & 1.654 & 918 & 2.572 \\
& $25.3 \%$ & $25.0 \%$ & $25.2 \%$ \\
\hline \multirow{2}{*}{ Total } & 6.543 & 3.679 & 10.222 \\
& $100.0 \%$ & $100.0 \%$ & $100.0 \%$ \\
\hline
\end{tabular}

Fonte: INEP (2011).

Ainda no que tange à leitura, o quesito leitura de sites da internet foi o único no qual os casos de sucesso escolar apareceram em porcentagem relativamente maior $(57,4 \%)$ que os casos de não sucesso $(47,4 \%)$. Mais do que a leitura em si, pode ser o acesso às novas tecnologias de informação o que faz mais a diferença. Nessa dimensão, os casos de sucesso utilizam mais a internet para leituras, se comparados aos casos de não sucesso escolar:

Tabela 4 - Leitura de Sites da Internet

\begin{tabular}{|c|c|c|c|}
\hline \multirow{2}{*}{ Leitura de sites da internet } & \multicolumn{2}{|c|}{ Sucesso escolar } & \multirow{2}{*}{ Total } \\
\cline { 2 - 3 } & Não & Sim & . \\
\hline \multirow{2}{*}{ Sempre ou quase sempre } & 3.130 & 2.126 & 5.256 \\
& $47.4 \%$ & $57.4 \%$ & $51.0 \%$ \\
\hline \multirow{2}{*}{ De vez em quando } & 1.801 & 1.009 & 2.810 \\
& $27.3 \%$ & $27.2 \%$ & $27.3 \%$ \\
\hline \multirow{2}{*}{ Nunca ou quase nunca } & 1.668 & 568 & 2.236 \\
& $25.3 \%$ & $15.3 \%$ & $21.7 \%$ \\
\hline \multirow{2}{*}{ Total } & 6.599 & 3.703 & 10.302 \\
& $100.0 \%$ & $100.0 \%$ & $100.0 \%$ \\
\hline
\end{tabular}

Fonte: INEP (2011)

Em relação ao turno, observa-se que os casos de sucesso escolar estão alocados, principalmente, no turno da manhã (51,6\%), noite $(24,3 \%)$ e tarde $(24,1 \%)$. Os casos de não sucesso escolar estão inseridos, em maiores proporções, no turno da noite $(45,3 \%)$, manhã $(31,8 \%)$ e tarde $(22,8 \%)$. Isso pode indicar que a família, muitas vezes, permite que o filho estude de manhã, possivelmente dedicando-se somente aos estudos em detrimento do trabalho, pelo menos enquanto não for reprovado. $\mathrm{O}$ aluno que é reprovado tende a ir para o turno da noite, em muitos casos precisando trabalhar durante o dia. Nota-se que apenas $29,9 \%$ dos casos de sucesso trabalham, enquanto que $44,5 \%$ dos casos de não sucesso escolar trabalham.

Quanto ao background familiar, percebe-se que tanto os casos de sucesso como os casos de não sucesso escolar moram, em média, com quatro ou cinco pessoas e, no geral, com a mãe. Observa-se que 10,9\% 
dos casos de não sucesso escolar não moram com a mãe, contra 2,9\% de casos de sucesso nessa situação. Em relação ao pai, 71,8\% dos casos de sucesso escolar moram com o pai e $63,7 \%$ dos casos de não sucesso moram. Adolescentes em famílias nucleares têm maior probabilidade de sucesso escolar, embora famílias monoparentais não sejam fadadas ao insucesso de seus filhos. A presença da mãe parece ser mais relevante que a do pai, o que está de acordo com a literatura. Um dado preocupante é que os casos de não sucesso escolar possuem quase o dobro de mães que não sabem ler e escrever (20,5\%), em relação aos casos de sucesso $(11,3 \%)$. Quanto à escolaridade do pai, verifica-se que na maioria dos casos de sucesso e não sucesso escolar o pai apresenta a escolaridade em torno do ensino fundamental incompleto. Todavia, observa-se que, embora a mãe e o pai não sejam escolarizados, ainda assim é possível ter uma trajetória escolar contínua, regular e sem defasagem, chegando com êxito ao terceiro ano do ensino médio, corroborando com a hipótese de que o background familiar influencia, porém não determina o sucesso escolar dos indivíduos.

Aprofundando um pouco mais o perfil dos alunos com relação a quando começaram a estudar, observa-se que $50,1 \%$ dos casos de sucesso escolar começaram a estudar na pré-escola, enquanto que 40,3\% dos casos de não sucesso escolar começaram a estudar na pré-escola. Menezes-Filho (2007), ao examinar o desempenho dos alunos de $4^{\mathrm{a}} \mathrm{e}$ $8^{\mathrm{a}}$ séries do ensino fundamental e da $3^{\mathrm{a}}$ série do ensino médio nos testes de proficiência em Matemática, observou que os alunos que fizeram pré-escola apresentaram um desempenho melhor em todas as séries em relação aos que entraram a partir da $1^{\mathrm{a}}$ série, concluindo que a idade de entrada no sistema de ensino representa um elemento importante. Nossos resultados estão de acordo, indicando que o ingresso na pré-escola desde a mais tenra idade pode ser um dos principais determinantes do sucesso escolar.

Quanto a gostar de estudar Língua Portuguesa, nota-se que as diferenças entre os casos de sucesso escolar e não sucesso são muito sutis: $75,5 \%$ dos casos de sucesso responderam gostar e 76,5\% dos casos de não sucesso também responderam gostar. No que diz respeito a fazer os deveres de casa dessa disciplina, praticamente não houve diferenças estatisticamente significativas entre os casos de sucesso e não sucesso. Em relação à Matemática, 62,9\% dos casos de sucesso afirmam gostar da matéria e 57,3\% dos casos de não sucesso escolar também afirmam gostar. As diferenças também não se mostram discrepantes quanto a fazer o dever de casa de Matemática. Aparentemente, gostar mais de uma determinada disciplina e fazer os deveres de casa exerceu influencia relativa na obtenção do sucesso escolar.

Os próximos dados referem-se a hábitos familiares de incentivo aos estudos, incentivo a realização dos deveres de casa, a leitura e a frequência às aulas, bem como os hábitos de conversar sobre os acontecimentos da escola. Nesses quesitos, observa-se que as diferenças en- 
tre os casos de sucesso escolar e não sucesso são pequenas, relativas e discretas. No caso do incentivo dos pais aos estudos, $98,2 \%$ dos casos de sucesso responderam ser incentivados e $96,1 \%$ dos casos de não sucesso escolar também responderam ser incentivados. No que tange o incentivo a realização dos deveres de casa, 92,9\% dos casos de sucesso alegaram ser incentivados e $89 \%$ dos casos de não sucesso alegaram ser incentivados. Quanto ao incentivo dos pais à leitura, 87,8\% dos casos de sucesso afirmaram ser incentivados e $85,7 \%$ dos casos de não sucesso escolar também afirmaram ser. Em relação ao incentivo em ir às aulas, $98 \%$ dos casos de sucesso disseram ser incentivados e 95,7\% dos casos de não sucesso afirmaram ser incentivados. No que diz respeito a conversar com os pais sobre os acontecimentos da escola, 73,8\% dos casos de sucesso responderam conversar e $69,4 \%$ dos casos de não sucesso escolar responderam conversar. Surpreendentemente, os dados parecem indicar que tais hábitos não foram tão decisivos na trajetória educacional desses indivíduos. Outros hábitos familiares merecem investigações complementares. Esse cenário não confirma a hipótese de que os hábitos individuais e familiares são potenciais determinantes do sucesso escolar.

Observa-se que o número de alunos matriculados no terceiro ano do ensino médio que conseguiu chegar a essa etapa na idade correta, de forma contínua e regular, foi consideravelmente baixo, especialmente entre os jovens em contextos sociais desfavoráveis. No entanto, embora os jovens que obtiveram sucesso escolar sejam exceções que fogem à regra, visto que a maioria de seus pares não obteve sucesso, eles comprovam que ainda assim é possível ter êxito, apesar de contextos sociais desfavoráveis. Isto quer dizer que nem tudo está perdido para os jovens em contextos sociais desfavoráveis, desde que políticas públicas se voltem a eles, possibilitando cada vez mais seu ingresso, permanência, fluxo e conclusão, no mínimo, da educação básica, uma vez que seu ingresso no ensino superior permanece como outro grande problema em aberto.

\section{Conclusão}

Neste trabalho buscou-se investigar o perfil dos jovens em contextos sociais desfavoráveis que chegaram com sucesso ao final do ensino médio. O sucesso foi compreendido como a chegada do aluno ao terceiro do ano ensino médio em idade apropriada, sem ter sido reprovado e sem ter abandonado a escola durante sua trajetória. Assim, optou-se por investigar o sucesso escolar entre os alunos em condições sociais desfavoráveis, isto é, não brancos, com mães menos escolarizadas e com pior nível socioeconômico. A escolha desses indivíduos como sujeitos da pesquisa deu-se em razão das desigualdades sociais perante o ensino, que comprometem fortemente a realização escolar dos indivíduos em condições sociais desfavoráveis, amplamente evidenciadas pela literatura cientifica. Conforme mencionado anteriormente, na 
Sociologia da Educação a definição de sucesso/insucesso escolar não é consensual. Contudo, são justamente as abordagens diversificadas que contribuem para o desvelamento das dimensões complexas subjacentes ao sucesso/insucesso escolar.

Ao longo desse trabalho discutiram-se problemas contemporâneos que afetam o ensino médio, buscando-se, juntamente, confrontar argumentos teóricos e empíricos sobre a realização educacional dos indivíduos e grupos. Assim, comparamos os pontos defendidos pelas Teorias do Capital Humano, pela teoria da Reprodução de Bourdieu, pelas proposições de autores como Boudon (1981) e Goldthorpe (2010), utilizando também os achados de pesquisas empíricas realizadas no Brasil sobre as desigualdades perante o ensino. Os resultados encontrados confirmam diversos achados da literatura científica pertinente, dentre os quais que as desigualdades sociais perante o ensino são grandes entraves à realização escolar dos indivíduos em condições sociais desfavoráveis, os quais enfrentam muitos obstáculos para manter-se na escola e obter sucesso.

Apesar de prognósticos teóricos e factuais contrários, constata-se também que muitos indivíduos, apesar das condições sociais desfavoráveis, atingem o sucesso escolar: $34 \%$ dos alunos não brancos, com mães menos escolarizadas e com o pior nível socioeconômico cursaram trajetórias regulares, sem reprovação e sem abandono, chegando sem distorção idade/série ao terceiro ano do ensino médio, comprovando que o background familiar influencia, porém não determina inexoravelmente a realização escolar dos indivíduos. Nesses casos, as teorias da ação racional, de fato, podem ser muito úteis na investigação das estratégias de escolarização dos indivíduos em condições sociais desfavoráveis. Os indivíduos atribuem valores aos diplomas, buscando caminhos, criando estratégias e se esquivando de constrangimentos em favor de sua realização escolar.

Em relação ao perfil dos jovens em contextos sociais desfavoráveis que chegaram com sucesso ao terceiro ano do ensino médio, não é possível indicar com exatidão, visto que as diferenças observadas entre os casos de sucesso escolar e não sucesso foram sutis e discretas, merecendo investigações complementares. De modo geral, o que podemos apreender sobre grande parte dos jovens que obtiveram sucesso escolar é que a maioria estava inserida em famílias nucleares, cuja mãe sabia pelo menos ler e escrever e o pai possuía escolaridade em torno do ensino fundamental incompleto; foram indivíduos que começaram a estudar na pré-escola, estudaram principalmente pela manhã, não trabalhavam e possuíam acesso à internet. Porém, também se observou que muitos indivíduos em contextos sociais desfavoráveis com outras características obtiveram sucesso escolar, e muitos indivíduos com características semelhantes não obtiveram sucesso, ou seja, identifica-se uma sutileza por trás do perfil desses indivíduos, que precisa ser investigada em profundidade. Essas sutilezas podem estar vinculadas, por 
exemplo, à própria singularidade das biografias, das interações, das redes de interdependências, das estratégias e/ou outros aspectos não capturados por essa investigação, mas agendados para pesquisas futuras. Conhecer melhor o perfil desses jovens pode ajudar as escolas a melhor se adaptarem a esses alunos, principalmente amortecendo os efeitos da origem social desfavorável sobre sua trajetória escolar.

Os problemas no sistema de ensino precisam ser resolvidos desde a pré-escola. Antes de chegar ao ensino médio, as trajetórias escolares atravessam um tortuoso percurso anterior, no qual se realizam muitas das desigualdades perante o ensino. Os alunos que passaram por alguma retenção nas etapas anteriores apresentam chances bem menores de concluir o ensino médio. O fluxo irregular (não aprovação) no ensino fundamental permanece como o maior obstáculo ao sucesso escolar. Observou-se que a maioria dos alunos que chegaram ao terceiro ano do ensino médio nunca foram reprovados, ou foram reprovados poucas vezes. O sistema escolar tem funcionado como um funil, em que muitos ingressam, mas poucos conseguem concluir, especialmente de forma regular e sem distorção idade/série, principalmente os alunos em condições sociais desfavoráveis. Nessa perspectiva, muito ainda precisa ser feito para viabilizar o direito à educação desses alunos.

Embora nos últimos anos as políticas públicas para educação tenham se expandido e realmente melhorado a oferta do ensino médio no país, ainda estão longe de resolver os muitos problemas que lhes assolam. A falta de atratividade do ensino médio (principalmente para os jovens provenientes de contextos sociais desfavoráveis), a precariedade das escolas públicas em relação à infraestrutura, tecnologias, conteúdo curricular e atividades extracurriculares, bem como as lacunas entre o ensino médio e o mundo do trabalho, dentre outros conhecidos problemas que incidem principalmente sobre os indivíduos mais pobres, dificultam as escolas de minimizarem os efeitos da origem social sobre a realização escolar, como é de se esperar. Dado o atual Plano Nacional de Educação e a promissora construção de uma Pátria Educadora, o contexto sociopolítico é favorável para de fato operar as medidas e reformas necessárias à equalização das oportunidades, diminuição das desigualdades e construção das bases necessárias ao desenvolvimento social e econômico das quais o Brasil (e seu futuro) depende.

Recebido em 30 de maio de 2015 Aprovado em 21 de dezembro de 2015

\section{Referências}

BECKER, Gary Stanley. The Age of Human Capital. In: LAZEAR, Edward Paul. Education in the Twenty First Century. Stanford: Hoover Institution Press, 2002. P. 3-8.

BOUDON, Raymond. A Desigualdade de Oportunidades. Brasília: UnB, 1981. BOURDIEU, Pierre. La Distinction: critique sociale du jugement. Paris: Minuit, 1979.

256 Educação \& Realidade, Porto Alegre, v. 41, n. 1, p. 239-258, jan./mar. 2016. 
BOURDIEU, Pierre; PASSERON, Jean-Claude. La Reproduction: éléments pour une théorie du système d'enseignement. Paris: Minuit, 1970.

BOURDIEU, Pierre; PASSERON, Jean-Claude. A Reprodução: elementos para uma teoria do sistema de ensino. Rio de Janeiro: Francisco Alves, 1975.

BRASIL. Lei no 13.005 de 25 de junho de 2014. Brasília: Distrito Federal, 2014. Disponível em: <http://www.planalto.gov.br/ccivil_03/_Ato2011-2014/2014/ Lei/L13005.htm>. Acesso em: 25 maio 2015.

CARRANO, Paulo. Não se Muda a Realidade do Ensino Médio Apenas Mexendo no Currículo. Portal IG, Brasília, 06 de janeiro de 2014. Disponível em: <http:// ultimosegundo.ig.com.br/educacao/2014-01-06/nao-se-muda-a-realidade-da-escola-apenas-mexendo-no-curriculo.html>. Acesso em: 25 maio 2015.

CASTELLS, Manuel. A Sociedade em Rede. Lisboa: Fundação Calouste Gulbenkian, 2002.

CASTRO, Maria Helena Guimarães. Uma Nova Agenda para a Educação Básica Brasileira. Com Ciência, Campinas, n. 132, 2011. Disponível em: <http://comciencia.scielo.br/ scielo.php?script=sci_arttext\&pid=S151976542011000800008 \&lng=pt\&nrm=iso $>$. Acesso em: 25 maio 2015.

COLEMAN, James Samuel et al. Report on Equality of Educational Opportunity. Washington: National Center For Educational Statistics, 1966.

DUBET, François. Le Déclin de L’institution. Paris: Éditions du Seuil, 2002.

FERREIRA, Vítor Sérgio; NUNES, Cátia. Para Lá da Escola: transições para a idade adulta na Europa. Educação em Foco, Juiz de Fora, v. 18, n. 3, p. 169-206, fev. 2014.

GOLDTHORPE, John Harry. Class Analysis and the Reorientation of Class theory: the case of persisting differentials in educational attainment. The British Journal of Sociology, online, v. 61, p. 311-335, jan. 2010. Disponível em: <http:// onlinelibrary.wiley.com/doi/10.1111/j.1468-4446.2009.01248.x/abstract>. Acesso em: 25 maio 2015.

HASENBALG, Carlos; SILVA, Nelson do Valle. Origens e Destinos: desigualdades sociais ao longo da vida. Rio de Janeiro: Topbooks, 2003.

HIRSCH, Fred. Limites Sociais do Crescimento. Rio de Janeiro: Zahar Editores, 1979.

IBGE - Instituto Brasileiro de Geografia e Estatística. Disponível em: <http:// www.ibge. gov.br/home/z. Acesso em: 16 maio 2015.

INEP - Instituto Nacional de Estudos e Pesquisas Educacionais Anísio Teixeira. Sistema de Avaliação de Educação Básica (SAEB). Brasília, 2011.

KRAWCZYK, Nora. Reflexão sobre Alguns Desafios do Ensino Médio no Brasil Hoje. Cadernos de Pesquisa, São Paulo, v. 41, n. 144, p. 752-769, set./ dez. 2011. Disponível em: <http://www.scielo.br/scielo.php?pid=S0100-1574201003006\&script=sci_abstract\&tlng=pt>. Acesso em: 25 maio 2015.

LAHIRE, Bernard. Sucesso Escolar nos Meios Populares: as razões do improvável. São Paulo: Ática, 1997.

MENEZES-FILHO, Naercio. Os Determinantes do Desempenho Escolar do Brasil. São Paulo: 2007. Disponível em: <http://jornalggn.com.br/sites/default/files/documentos/ desempenho_escolar.pdf $\geq$. Acesso em: 25 maio 2015.

MONT'ALVÃO, Arnaldo. Estratificação Educacional no Brasil do Século XXI. DADOS, Rio de Janeiro, v. 54, n. 2, p. 389-430, 2011. Disponível em: <http://www. scielo.br/ pdf/dados/v54n2/v54n2a06 . Acesso em: 25 maio 2015. 
NOGUEIRA, Cláudio Marques Martins; FORTES, Maria de Fátima. A Importância dos Estudos sobre Trajetórias Escolares na Sociologia da Educação Contemporânea. Paidéia, Belo Horizonte, v.3, n.2, p. 57-74, 2004. Disponível em:<http:// www.fumec.br/revistas/ index.php/paideia/article/viewFile/1339/910>. Acesso em: 17 dez. 2015.

NOGUEIRA, Maria Alice; NOGUEIRA, Cláudio Marques Martins. Bourdieu e a Educação. Belo Horizonte: Autêntica, 2004.

NOGUEIRA, Maria Alice. A Sociologia da Educação do Final dos Anos 60/início dos anos 70: o nascimento do paradigma da reprodução. Em Aberto, Brasília, v. 9, n. 46, p. 49-58, abr/jun. 1990. Disponível em: <http://www.emaberto.inep.gov. br/index.php/emaberto/article/ viewFile/727/650 . Acesso em: 25 maio 2015.

PAIS, José Machado; FERREIRA, Vítor Sérgio (Org.). Tempos e Transições de Vida: Portugal ao espelho da Europa. Lisboa: Imprensa de Ciências Sociais, 2010.

PLOWDEN Report. Children and Their Primary School: a Report of the Central Advisory Council for Education (England). London: Her Majesty's Stationery Office (HMSO), 1967.

SCHULTZ, Theodore. The Reckoning of Education as Human Capital. In: HANSEN, Lee (Org.). Education, Income and Human Capital. New York: NBER Books, 1970. P. 297-306.

TAVARES JR., Fernando; FERES, Flávia Lúcia Chein; FREGUGLIA, Ricardo da Silva. A Produção da Exclusão Educacional no Brasil. Educação em Foco, Juiz de Fora, v. 18, n. 3, p. 51-81, fev. 2014.

TAVARES JR., Fernando. Limites Sociais da Educação no Brasil: estratificação, mobilidade social e ensino superior. 2007. $273 \mathrm{f}$. Tese (Doutorado em Sociologia) - Programa de Pós-Graduação em Ciências Sociais, Instituto Universitário de Pesquisas do Rio de Janeiro, Rio de Janeiro, 2007.

VIEIRA, Maria Manuel; PAPPÁMIKAIL, Lia; NUNES, Cátia. Escolhas Escolares e Modalidades de Sucesso no Ensino Secundário: percursos e temporalidades. Sociologia Problemas e Práticas, Lisboa, n. 70, p. 45-70, set./dez. 2012. Disponível em: <http://sociologiapp.iscte.pt/pdfs/10300/10442.pdf $\geq$. Acesso em: $17 \mathrm{dez}$. 2015.

Vanessa Gomes de Castro é doutoranda em Ciências Sociais no Programa de Pós-Graduação em Ciências Sociais da Universidade Federal de Juiz de Fora (PPGCSO/UFJF). Mestre em Ciências Sociais pelo mesmo programa. Especializada em Políticas Públicas e Gestão Social pela Universidade Federal de Juiz de Fora.

E-mail:vadecastro@hotmail.com

Fernando Tavares Júnior é professor Adjunto e Chefe do Departamento de Ciências Sociais, membro do Programa de Pós-Graduação em Ciências Sociais (PPGCSO) da Universidade Federal de Juiz de Fora (UFJF) e Coordenador do Grupo de Pesquisa em "Equidade, Políticas e Financiamento da Educação Pública” do Centro de Políticas Públicas e Avaliação da Educação (CAED). Doutor em Sociologia (IUPERJ).

E-mail: ftavares@caed.ufjf.br 